\title{
Analysis of static and dynamic parameters of the wooden window glass frame
}

\author{
Zuzana Papánová ${ }^{1 *}$ and Daniel Papán ${ }^{1}$
}

${ }^{1}$ University of Žilina, Faculty of Civil Engineering, Department of Structural Mechanics and Applied Mathematics, Univerzitná 8215/1, 01026 Žilina, Slovak Republic

\begin{abstract}
An integral part of each the window is its frame. This frame is a support of the glass panel. It is a part of window used for any load distribution to the other parts of buildings. Investigation of parameters of this member acting in the interaction system (glass-frame) is important for numerical modelling and simplified analytical solution. The main aim of the paper is to present experimental investigation of the static and dynamic parameters results of usual wooden and plastic windows.
\end{abstract}

\section{Introduction}

Window structures, respectively window fillings are the most exposed elements of buildings facades and structures. Its features have a significant degree share optimum internal environment and decisive in terms of energy losses objects. Windows are not only a significant construction elements, but also expressive means of the architecture.
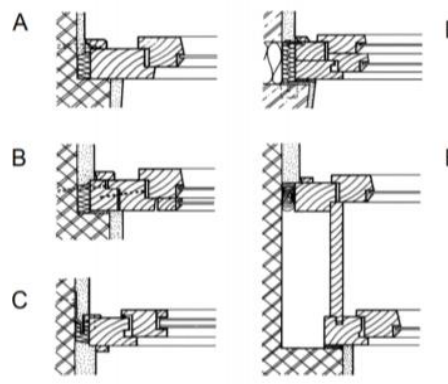

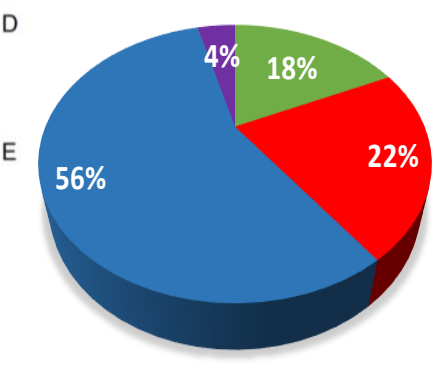

Europe

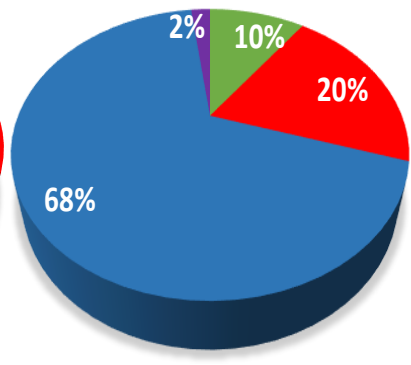

Slovakia

Fig. 1. The windows types and material representation [1].

In Fig. 1 the common types of standard windows compositions are presented: A - single window with one glass, B - single window with associated leaf, $\mathrm{C}$ - single window with double glazing, D - double window, E - double window. There is also material representation

* Corresponding author: zuzana.papanova@uniza.sk 
in Slovakia and in Europe in this figure. The blue colour represents PVC, the green colour represents wood, the red colour represents alloy and the purple colour represents other composites. One of the main parts of the window is the glass frame. It creates the support for the glass filling and carries the toad of it. In this paper the real case study of traditional window frame type $\mathrm{D}$ is presented. The main aim of the research presented is to obtain the basic static and dynamic parameters of wooden material. These parameters are important for modelling of the blast resistance of windows [2].
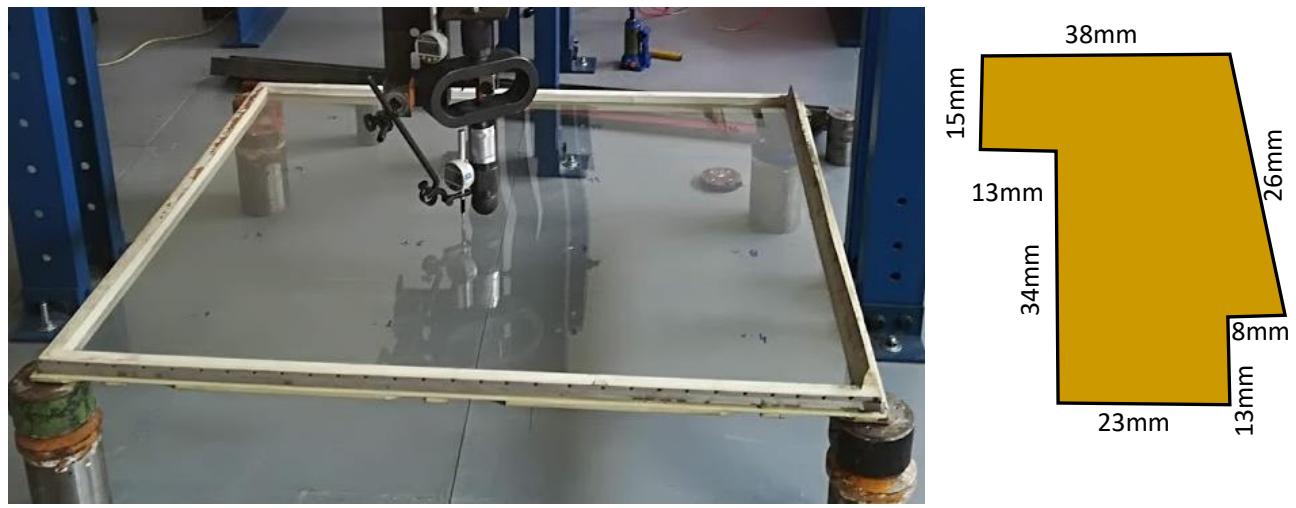

Fig. 2. The tested window glass frame - type D and its cross-section dimensions.

The tested window glass frame was used from demounted real window from more than 40 years old building. The dimensions of the frame were $1.2 \mathrm{~m} \mathrm{x} 1.05 \mathrm{~m}$. The cross-section dimensions and the tested window part are showed on Fig. 2.

\section{Dynamic test of the window frame - two natural frequencies analysis}

For the purpose of the research the finite element (FE) model was created in the Visual FEA system. The volume elements with simplified geometry of the frame were used.

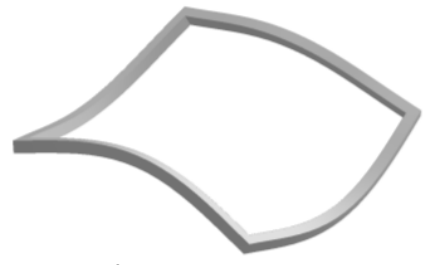

$f_{(1)}$

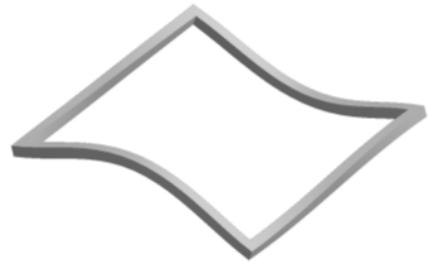

$f_{(4)}$

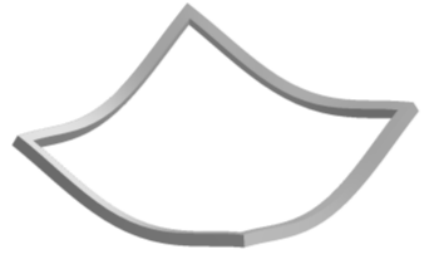

$f_{(2)}$

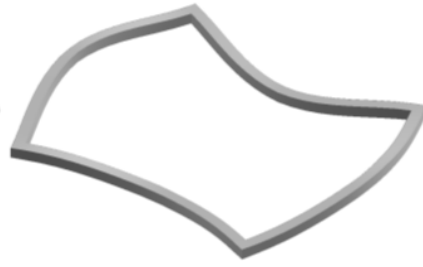

$f_{(5)}$
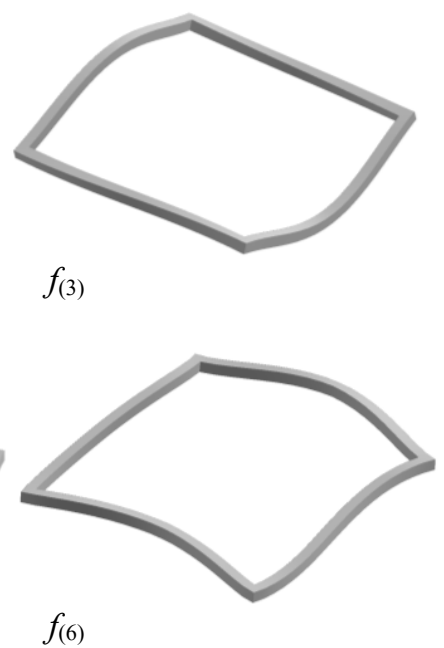

Fig. 3. The first six modes of natural vibration obtained from FEM model. 
The supports respect the experimental measurement situation. In the corners the XYZ hinges were modelled. The examples of first 6 natural modes are in the Fig. 3.

The results of the dynamic FEM analysis - natural modes and the natural frequencies are in the Fig. 3 and in the Table 1. The Table 1 also contains the sensitivity analysis resp. Dependence of the first two natural frequencies on the dynamic modulus of elasticity and the Poisson ratio. The unit weight of the material was $480 \mathrm{~kg} / \mathrm{m}^{3}$.

Table 1. Dependence of natural frequencies on FE model material characteristics.

\begin{tabular}{|c|c|c|c|c|c|c|c|c|c|c|}
\hline \multirow{3}{*}{$\begin{array}{c}\boldsymbol{E}_{d y n} \\
{[\text { Gpa] }}\end{array}$} & \multicolumn{10}{|c|}{ Poisson's ratio } \\
\hline & \multicolumn{2}{|c|}{0.45} & \multicolumn{2}{|c|}{0.46} & \multicolumn{2}{|c|}{0.47} & \multicolumn{2}{|c|}{0.48} & \multicolumn{2}{|c|}{0.49} \\
\hline & $\begin{array}{c}f_{(1)} \\
{[\mathbf{H z}]}\end{array}$ & $\begin{array}{c}f_{(2)} \\
{[\mathrm{Hz}]}\end{array}$ & $\begin{array}{c}f_{(\mathbf{1})} \\
{[\mathbf{H z}]}\end{array}$ & $\begin{array}{c}f_{(2)} \\
{[\mathbf{H z}]}\end{array}$ & $\begin{array}{c}f_{(\mathbf{1})} \\
{[\mathrm{Hz}]}\end{array}$ & $\begin{array}{l}f_{(2)} \\
{[\mathbf{H z}]}\end{array}$ & $\begin{array}{c}f_{(1)} \\
{[\mathrm{Hz}]}\end{array}$ & $\begin{array}{c}f_{(2)} \\
{[\mathbf{H z}]}\end{array}$ & $\begin{array}{c}f_{(\mathbf{1})} \\
{[\mathrm{Hz}]}\end{array}$ & $\begin{array}{c}f_{(2)} \\
{[\mathrm{Hz}]}\end{array}$ \\
\hline 8.9 & 43.2 & 51.6 & 44.1 & 52.0 & 45.0 & 52.4 & 45.9 & 52.7 & 46.8 & 53.1 \\
\hline 9.0 & 43.4 & 51.8 & 44.3 & 52.2 & 45.2 & 52.6 & 46.1 & 53.0 & 47.0 & 53.4 \\
\hline 9.1 & 43.6 & 52.1 & 44.5 & 52.5 & 45.4 & 52.8 & 46.3 & 53.2 & 47.2 & 53.6 \\
\hline 9.2 & 43.8 & 52.3 & 44.7 & 52.7 & 45.6 & 53.1 & 46.5 & 53.5 & 47.5 & 53.9 \\
\hline 9.3 & 44.0 & 52.5 & 44.9 & 52.9 & 45.8 & 53.3 & 46.8 & 53.7 & 47.7 & 54.1 \\
\hline 9.4 & 44.2 & 52.8 & 45.1 & 53.2 & 46.0 & 53.6 & 47.0 & 54.0 & 47.9 & 54.4 \\
\hline 9.5 & 44.4 & 53.0 & 45.3 & 53.4 & 46.3 & 53.8 & 47.2 & 54.2 & 48.1 & 54.6 \\
\hline
\end{tabular}

The dynamic experimental measurements of the dynamic response in each midpoint of all four spans arranged as in Fig. 1 was measured. The excitation was performed by vertical slide typing with fingers on the frame. Bruel Kjaer Pulse system with piezoelectric accelerometers BK 4508 and LAN-XI Type 3050 - Multi-purpose 6-channel input module was used for measurements. The averaged amplitude autospectrum in the mid-span points with peak detection is showed in Fig. 4.

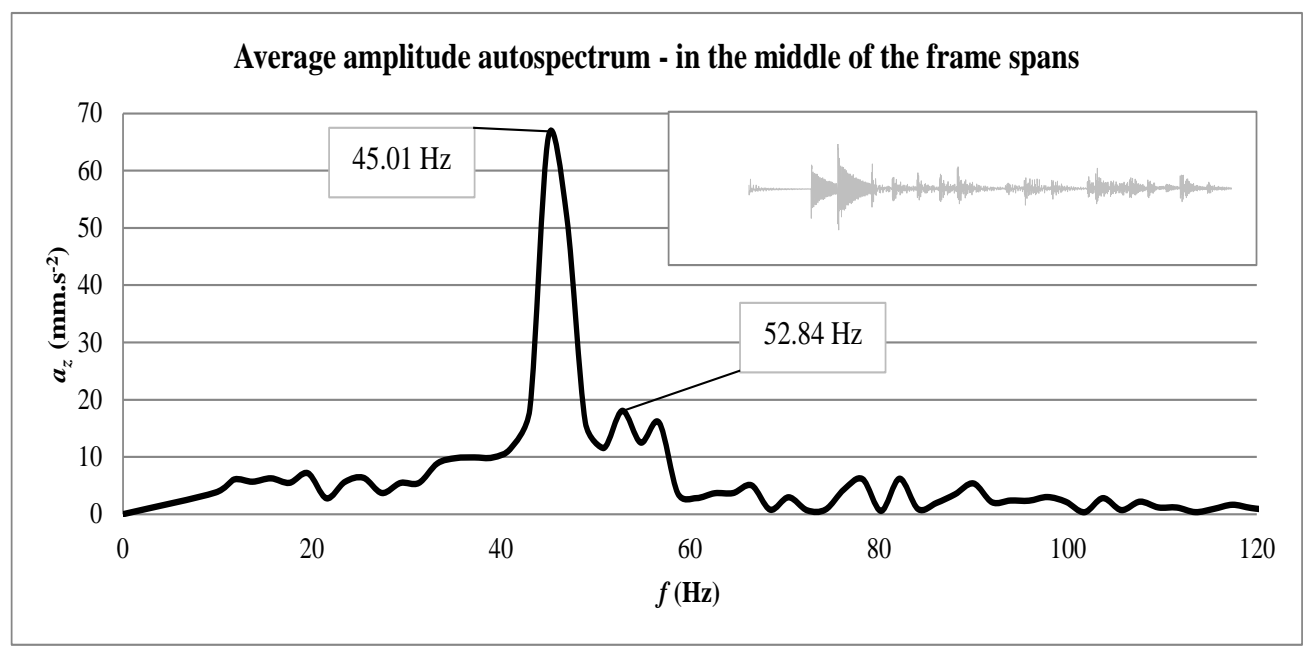

Fig. 4. The averaged vertical amplitude autospectrum in mid-span points.

There is also an example of the vertical acceleration time history in Fig. 4. The amplitude peaks indicates the natural frequencies of the frame and it is possible to find the nearest values 
in the FE solution in Table 1. These frequencies determinate the basic material parameters of the wood of the window glass frame.

\section{Static test of the window frame non-standard evaluation approach}

For the purpose - material properties identification was applied two methods of approaches. Precision measurement of deformed surface of the frame and the theoretical principles of basic contact mechanics were used. The topographic system Zephyr 3DF 4.530 is the software solution by 3Dflow to automatically deal with any $3 \mathrm{D}$ reconstruction and scanning challenge. It allows to automatically reconstruct a $3 \mathrm{D}$ model starting from a set of pictures. The process is completely automatic, as no coded targets, manual editing or special equipment are needed. For this type of analysis digital single-lens reflex camera Nikon D5600 with 18-55 AF-P VR lens were used. A set of 17 HD pictures were analysed. Average dimensions of the surface sphere section deformed during load test were automatically evaluated from Zephyr 3DF system. [3] The evaluated parameters of the contact are depth $d$ $=2.4 \mathrm{~mm}$ and radius $a=28.6 \mathrm{~mm}$. The parameters $a, d$ are described in Fig. 5 .
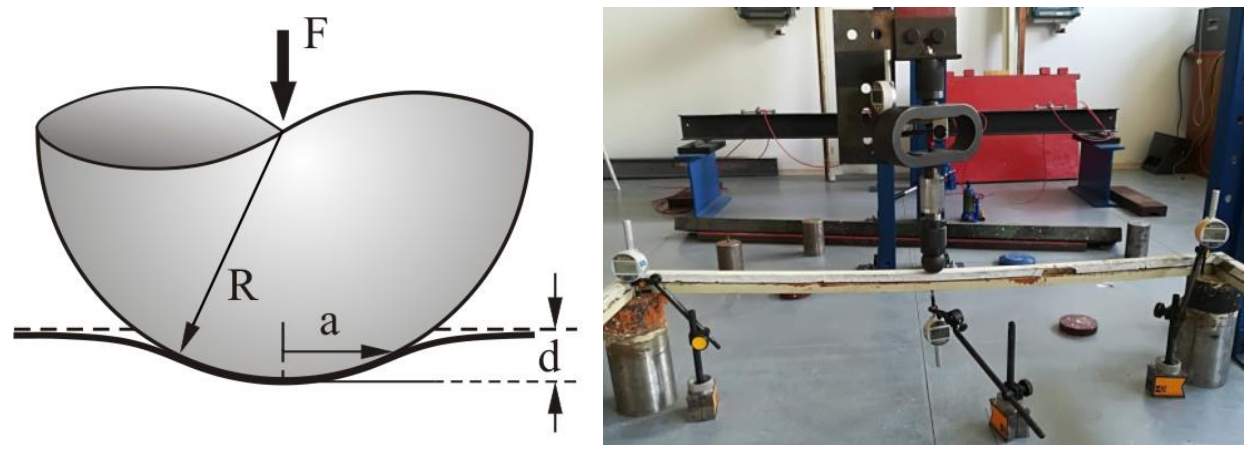

Fig. 5. Parameters of the evaluated contact while static load test of the wooden window glass frame.

Classical solutions for non-adhesive elastic contact theory with measured parameters of deformed sphere section on the frame were applied. Based on well-known Hertz [4] equations the static wood modulus of elasticity was calculated. The followed equations were applied:

$$
\begin{gathered}
a=(R \cdot d)^{1 / 2} \\
F=\left(4 \cdot E^{\circ} \cdot R^{1 / 2} \cdot d^{3 / 2}\right) / 3 \\
1 / E^{\circ}=\left(1-v_{1}^{2}\right) / E_{1}+\left(1-v_{2}^{2}\right) / E_{2}
\end{gathered}
$$

where $R$ is diameter of the sphere of loaded equipment. In this case study $R=52 \mathrm{~mm}$. The material of the sphere is steel S 235 with $E_{1}=2.1 \cdot 10^{11} \mathrm{~Pa}$ and $v_{1}=0.3$.

For the investigated window glass frame were performed static load tests until to $F=500$ $\mathrm{N}$. Because the frame is painted with oil colour and the colour film is stiff and fragile the spherical section stays projected on the surface. If the prediction for $v_{1}=0.46$ the only one parameter $E_{2}$ can be calculated from equations 1-3. Also $E^{\circ}$ is reference Young's modulus of elasticity for connected materials. The most important input values are measured geometric parameters of the spherical section projected to the film colour on the window glass frame projection. If the material „1" is the steel and the material " 2 " is wood than the modulus of 
elasticity calculated based on evaluated parameters is $E_{2}=9.2 \mathrm{GPa}$. This average Young's modulus values of wood are along the longitudinal axis.
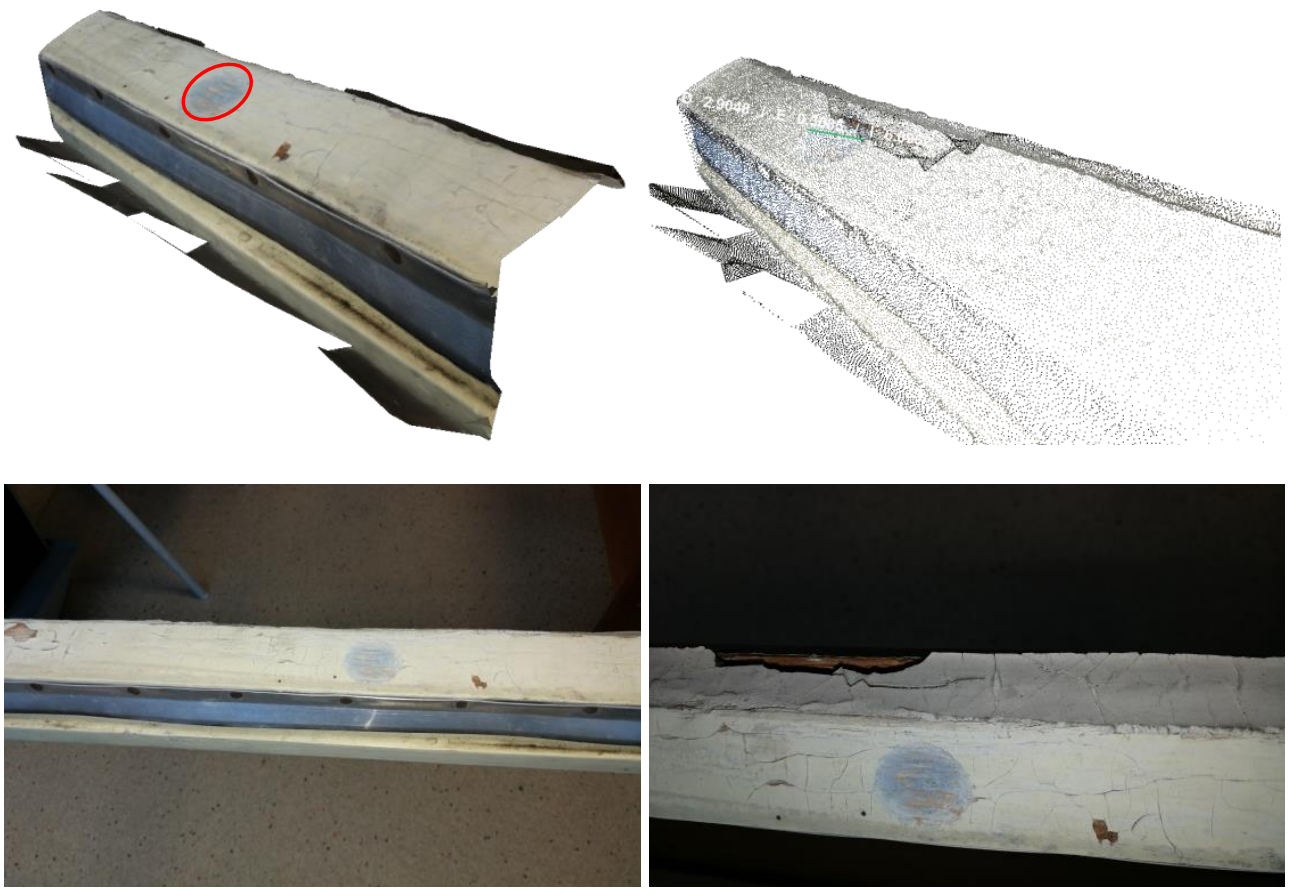

Fig. 6. Zephyr 3DF analysis and measurement of contact geometric parameters example.

The process of the bitmaps transformation to the point cloud with precision 3D coordinates implemented in Zephyr 3DF is simply exampled in Fig. 6. These method basics are in the stereo-photogrammetry. It involves estimating the three-dimensional coordinates of points on an object employing measurements made in two or more photographic images taken from different positions. For the measurements requested in this analysis the precision is depended on the snapshots set resolution and variability and number of samples. A line of sight (or ray) can be constructed from the camera location to the point on the object. It is the intersection of these rays (triangulation) that determines the three-dimensional location of the point. The lens aperture is also important quality parameter for data acquisition process. The modern methods of measurements can help standard analytical evaluations of physical or mechanical phenomenon.

\section{Conclusions}

This parametric case study of basic material elastic parameters of wooden window glass frame is part of the research focused to special dynamic resistant of standard windows common used in Slovakia. This research is the part of wide international investigation of the real windows behaviour in extreme dynamic load.

Because the windows are strongly exposed to straight impact of load it is necessary to describe parameters and their evaluation due to experimental tests. This paper shows the inlabo investigation approach to obtain the relevant basic material constants values of the second most impacted (the first is glass filling) part of windows structure-glass frame. Relatively wide range of elasticity modulus and the Poissson's ratios needs the simply tests procedures to evaluate exact parameters for each investigated window part. Nowadays 
powerful software and hardware tools enable us to make more realistic FEM simulations. This analysis expects precision inputs. The investigated material parameters presented in the paper will be used in further sophisticated analysis in cooperation with Tierste University researchers. Averaged (statistically evaluated from more measurements) values as the main results in static and dynamic mode are red signed in chapters of the paper. The future research will focused to the integral parts of the windows - connection glass frame to glass filling. Investigation which can use the results of this paper is in [5].

Authors kindly acknowledge to Department of Structural Mechanics and Applied Mathematics, Faculty of Civil Engineering, University of Žilina for support in experimental investigation.

\section{References}

1. P. Suchánek, TZB web portal, (2012)

2. L. Figuli, Ch. Bedon, D. Papán, Z. Papánová, ANCRiSST, Sapienza University Press, 123-127 (2019)

3. 3DF Zephyr Pro - 3d models from photos - 3Dflow, www.3dflow.net. Retrieved (2017)

4. V. Popov, M. Heß, Willert, E, Handbook of Contact Mechanics: Exact Solutions of Axisymmetric Contact Problems, (Springer Nature, Switz., 2019)

5. P. W. Sielicky, Ch. Bedon, X. Zhang, Soft target protection: Theoretical Basis and Practical Measuremnts (Springer Nature, Switz., 2020) 